\title{
TO STUDY THE ASSOCIATION OF THYROID DYSFUNCTION IN CHRONIC OBSTRUCTIVE PULMONARY DISEASE PATIENTS (A CROSS SECTIONAL PREVALENCE STUDY SINGLE CENTRE ONLY)
}

\author{
Snehlata Verma1, Sandhya Gautam², Uday Bhan ${ }^{3}$, Devendra Kumar Vohra ${ }^{4}$, Abha Gupa $^{5}$, Santosh Mittal6, Ganesh Singh ${ }^{7}$ \\ ${ }_{1}^{1}$ Assistant Professor, Department of Medicine, LLRM Medical College, Meerut, Uttar Pradesh, India. \\ ${ }^{2}$ Associate Professor, Department of Medicine, LLRM Medical College, Meerut, Uttar Pradesh, India. \\ 3IIIrd Year Postgraduate, Department of Medicine, LLRM Medical College, Meerut, Uttar Pradesh, India. \\ ${ }_{4}^{4}$ Associate Professor, Department of Medicine, LLRM Medical College, Meerut, Uttar Pradesh, India. \\ 5 Professor, Department of Medicine, LLRM Medical College, Meerut, Uttar Pradesh, India. \\ ${ }^{6}$ Associate Professor, Department of Medicine, LLRM Medical College, Meerut, Uttar Pradesh, India. \\ ${ }^{7}$ Associate Professor, Department of Medicine, LLRM Medical College, Meerut, Uttar Pradesh, India.
}

\section{BACKGROUND}

ABSTRACT

COPD is a major cause of chronic morbidity and mortality throughout the world, leading to years of suffering and premature death from it or its complications. Thyroid hormone regulates the metabolism of proteins, lipids and carbohydrates, and controls the activity of membrane bound enzymes. Thyroid hormone enhances mitochondrial oxidation, and thus, augments metabolic rate. This effect on metabolic rate is probably responsible for the association between the thyroid hormone and respiratory drive. Severity of airway obstruction, hypoxemia, and systemic inflammation may predispose to subclinical hypothyroidism, overt hypothyroidism and non-thyroid illness syndrome. This study was conducted to evaluate the prevalence of thyroid dysfunction in COPD patients.

\section{METHODS}

This is a cross-sectional, prevalence study. The study was conducted over the period 2017-2018. The study group consisted of male and female COPD patients diagnosed with spirometry and severity was determined according to GOLD criteria. Patients were enrolled in this study from medicine department OPD/IPD. Patients were screened for thyroid dysfunction.

\section{RESULTS}

Out of 121 patients, thyroid dysfunction was present in 45 patients. 11 were subclinical hypothyroidism, 33 hypothyroidism and 1 hyperthyroidism. The prevalence of thyroid dysfunction was $37.2 \%$. In stage A it was $25.8 \%$, stage B $37.5 \%$, Stage C $46.6 \%$ and in stage D 39.3\%. Thyroid dysfunction was more in smoker COPD patient. Mean FEV1 was less in COPD patients with thyroid dysfunction.

\section{CONCLUSIONS}

Thyroid dysfunction is a common extrapulmonary manifestation in COPD patients. Mean FEV1 was decreasing more in COPD patients with thyroid disorders than euthyroid COPD patients. As the staging increases, thyroid dysfunction increases and affects the quality of life in these patients.

\section{KEY WORDS}

COPD, Hypothyroidism, Thyroid Dysfunction, FEV1, Stage

HOW TO CITE THIS ARTICLE: Verma S, Gautam S, Bhan U, et al. To study the association of thyroid dysfunction in chronic obstructive pulmonary disease patients (a cross sectional prevalence study single centre only). J. Evolution Med. Dent. Sci. 2019;8(28):2230-2233, DOI: 10.14260/jemds/2019/488

\section{BACKGROUND \\ Chronic Obstructive Pulmonary Disease (COPD) is a major} cause of chronic morbidity and mortality throughout the world. COPD ranks second to coronary heart disease among people over 40 years age especially those who have been chronic and heavy smoker. The global burden of disease study has projected that COPD which ranked sixth as the cause of death in 1990, will become the third leading cause of death world-wide by 2020.1

'Financial or Other Competing Interest': None.

Submission 16-03-2019, Peer Review 24-06-2019,

Acceptance 05-07-2019, Published 15-07-2019.

Corresponding Author:

Dr. Sandhya Gautam,

R-21, Medical College Campus,

Meerut,

Uttar Pradesh, India.

E-mail: sandyg.3080@gmail.com

DOI: $10.14260 /$ jemds $/ 2019 / 488$

\section{(c) (i) $\$$}

There is now increasing evidence available to say that COPD is a systemic inflammatory response to identifiable stimuli, affecting predominantly lungs and numerous other organs like thyroid, pituitary etc. The thyroid hormone regulates the metabolism of proteins, lipids and carbohydrates, and controls the activity of membrane bound enzymes. The thyroid hormone enhances mitochondrial oxidation, and thus, augments metabolic rate. This effect on metabolic rate is probably responsible for the association between the thyroid hormone and respiratory drive. The primary physiological abnormality in COPD is an accelerated decline in forced expiratory volume in one sec (FEV1). The disease course begin with an asymptomatic phase in which lung function deteriorates without associated symptoms and since symptoms may not occur until lung functions are substantially reduced, early detection is enhanced by spirometry. Guidelines from the Global Initiative for COLD (GOLD) states that the airflow limitation in COPD is characterized by a FEV1 value $<80 \%$ predicted of normal 
value and FEV1/FVC $<0.70 .{ }^{1}$ Hypothyroidism may also cause alveolar hypoventilation, decreased lung volumes, upper airway obstruction, depression in respiratory stimulus and respiratory failure. ${ }^{2}$ Hypoxia and decreased ventilatory response to hypercapnia have been demonstrated in patients with hypothyroidism. Diaphragmatic dysfunction and myopathies can be seen in patients with hypothyroidism. Inspiratory and expiratory muscles strength is linearly related to the degree of hypothyroidism. Hypoxia and hypercapnia cause destruction in sella turcica and pituitary gland dysfunction. ${ }^{3}$ During the course of COPD, together with hypoxia, peripheral metabolism of thyroid hormone changes and thyroid hormone levels decrease in patients with very severe COPD. Several characteristics of COPD patients could potentially increase their likelihood of developing hypothyroidism or hyperthyroidism. Impaired thyroid function in COPD may present as subclinical hypothyroidism, overt hypothyroidism, and non-thyroid illness syndrome. ${ }^{4}$ Non-thyroid illness syndrome has decreased levels of the biologically active hormone T3 and normal or decreased levels of the prohormone T4. Serum levels of the TSH are usually normal, though they can be low in the most severely ill patients. ${ }^{5}$ Hyper metabolism is commonly observed in patients with chronic obstructive pulmonary disease. A hyper metabolic state in combination with insufficient dietary intake will result in a negative energy balance and may conceivably contributed to weight loss in chronic obstructive pulmonary disease. ${ }^{6}$ According to R. Prakash, M. Harish, V. Surynarayana et al, several factors such as hypoxemia, exacerbation, drugs, malnutrition may lead to endocrinal changes in chronic obstructive pulmonary disease especially Thyroid function abnormality. Low T3 and T4 with high TSH concentration in patients with chronic obstructive pulmonary disease reflects the nonthyroidal illness syndrome. ${ }^{7}$

\section{Aims and Objectives}

To determine the prevalence of thyroid dysfunction in patients of chronic obstructive pulmonary disease and to assess and correlate the thyroid hormone dysfunction with chronic obstructive pulmonary disease severity.

\section{METHODS}

This study was conducted at Department of Medicine LLRM Medical College and SVBP Hospital Meerut during 2017-2018. The study was cross sectional prevalence study included patients of COPD admitted in the medicine ward and attending medicine OPD. Sample size was 121 patients with 90 male and 31 female and divided into 4 groups, Group A mild (31 patient), Group B moderate (32 patient), Group C severe (30 patient), Group D very severe (28 patient) according to GOLD criteria. The patients were subjected to detailed history regarding the presentation, duration of illness, personal antecedent including history of smoking using detailed questionnaire. Patients included in the study was subjected to a thorough general and systemic examination especially respiratory system.

\section{Inclusion Criteria}

Patients of both sexes between the age of 47 to 88 years with COPD diagnosed on the basis of history and PFTs findings mentioned above and given the consent for participation in the study.

\section{Exclusion Criteria}

- Patients with known chronic restrictive chest diseases.

- Patients with known thyroid disorder or previous thyroid surgery.

- Patients with other diseases or illnesses that might affect thyroid functions e.g., endocrinal, metabolic, autoimmune disorders, etc.

- $\quad$ Patients on any regular medication, other than the COPD drugs, that might affect thyroid functions, such as iodinecontaining drugs, amiodarone and immunosuppressive drugs.

A written informed consent was taken from all patients and detailed history and examination was done. In the clinical history, duration of COPD with a history of exacerbation and treatment were elicited. History of the presence of risk factors such as smoking, exposure to fumes (biomass), and the presence of any other chronic disease was inquired, history of previous thyroid dysfunction or treatment of thyroid dysfunction taken chest surgery/ Thyroid surgery. Thereafter, the detailed physical examination was carried out. Complete hemogram, blood urea nitrogen, serum creatinine, arterial pulmonary function test by spirometry, and FT3/ FT4/ thyroid stimulating hormone (TSH) was done.

\section{Data Analysis}

The data was tabulated in MS Excel. It was analysed with IBM SPSS (Statistical Package for Social Sciences) version 21. For parametric quantitative data the results are depicted as mean and standard deviation, comparisons were made by chi square test and one-way ANOVA for comparisons of quantitative variables between more than two categories, $\mathrm{p}$ value was considered significant at $\mathrm{p}<0.05$.

\section{RESULTS}

The study was conducted in department of medicine, LLRM Medical College and Associated SVBP Hospital, Meerut U.P. 121 Subjects attending medicine OPD and/ or admitted in medicine ward were included in the study. Patients were divided in 4 groups group A mild, group B moderate, group C severe, group D very severe according to GOLD criteria on the PFT FEV1 (Premed), FEV1(Postmed), FEV1/FVC finding. Group A mild included FEV1(Postmed) $\geq 80 \%$, Group B moderate included FEV1 (Postmed) 50-80\%, Group C severe included FEV1 (postmed) 30 - $50 \%$, Group D very severe included FEV1 $\leq 30 \%$.

\begin{tabular}{|c|c|}
\hline Stage & Characteristics \\
\hline 0: At risk & Chronic symptoms (cough and sputum production) \\
\hline 1: Mild COPD & $\begin{array}{l}\text { With/ without chronic symptoms (cough and sputum production) } \\
\text { FEV1 } 80 \% \text { of predicted } \\
\text { FEV1/ FVC }<70 \% \text { mild airflow limitation }\end{array}$ \\
\hline $\begin{array}{l}\text { 2: Moderate } \\
\text { COPD }\end{array}$ & $\begin{array}{l}\text { Usually chronic symptoms (cough and sputum production) with } \\
\text { shortness of breath developing on exertion. } \\
\text { FEV1 between } 80-50 \% \text { of predicted FEV1/FVC }<70 \% \text {, worsening } \\
\text { airflow limitation }\end{array}$ \\
\hline $\begin{array}{c}\text { 4. Very Severe } \\
\text { COPD }\end{array}$ & $\begin{array}{c}\text { Chronic symptoms (Cough and sputum production with increased } \\
\text { shortness of breath and repeated exacerbations). } \\
\text { FEV1 between } 50-30 \% \text { of predicted FEV1/FVC }<70 \% \text {, further } \\
\text { worsening airflow limitation. } \\
\text { Chronic symptoms (Cough and sputum production) } \\
\text { Severe shortness of breath or chronic respiratory failure. } \\
\text { Severe airflow limitation (FEV1 may be } 30 \% \text { or even less). }\end{array}$ \\
\hline & Gold Criteria for COPD \\
\hline
\end{tabular}




\begin{tabular}{|c|c|c|c|c|}
\hline Group & No. of Patients & Male & Female & Mean Age (Yrs.) \\
\hline A & 31 & $22(70.96 \%)$ & $9(29.04 \%)$ & $56.32 \pm 6.78$ \\
\hline B & 32 & $24(75 \%)$ & $8(25 \%)$ & $59.69 \pm 9.61$ \\
\hline C & 30 & $23(76.66 \%)$ & $7(23.34 \%)$ & $62.03 \pm 8.92$ \\
\hline D & 28 & $21(75 \%)$ & $7(25 \%)$ & $65.39 \pm 7.81$ \\
\hline Table 1. Gender Wise Distribution and Mean Age among different \\
Group of COPD Patients \\
\hline
\end{tabular}

\begin{tabular}{|c|c|c|c|}
\hline Age & Male & Female & Total \\
\hline $41-50$ & $14(11.7 \%)$ & $6(4.8 \%)$ & $20(16.5 \%)$ \\
\hline $51-60$ & $39(32.5 \%)$ & $12(9.6 \%)$ & $51(42.1 \%)$ \\
\hline $61-70$ & $28(23.3 \%)$ & $9(7.2 \%)$ & $37(30.5 \%)$ \\
\hline 71- 80 & $8(6.7 \%)$ & $3(2.4 \%)$ & $11(9.1 \%)$ \\
\hline \multirow[t]{2}{*}{$81-90$} & $1(.8 \%)$ & $1(.8 \%)$ & $2(1.6 \%)$ \\
\hline & $90(74.4 \%)$ & $31(25.6 \%)$ & $121(100 \%)$ \\
\hline
\end{tabular}

\begin{tabular}{|c|c|c|}
\hline Group & Euthyroid & Thyroid Dysfunction \\
\hline $\mathrm{A}(\mathrm{N}=31)$ & 23 & $08(25.80 \%)$ \\
\hline $\mathrm{B}(\mathrm{N}=32)$ & 20 & $12(37.50 \%)$ \\
\hline $\mathrm{C}(\mathrm{N}=30)$ & 16 & $14(46.66 \%)$ \\
\hline $\mathrm{D}(\mathrm{N}=28)$ & 17 & $1(39.28 \%)$ \\
\hline \multicolumn{3}{|c|}{ Table 3. Comparison of Thyroid Dysfunction among different Group of } \\
COPD Patients \\
\hline
\end{tabular}

\begin{tabular}{|c|c|}
\hline Thyroid Status & No. of Patients \\
\hline Euthyroid & 76 \\
\hline Subclinical hypothyroidism & 11 \\
\hline Hypothyroidism & 33 \\
\hline Hyperthyroidism & 1 \\
\hline Total & 121 \\
\hline Table 4. Comparison among Euthyroid and Thyroid Dysfunction in \\
COPD Patients \\
\hline
\end{tabular}

\begin{tabular}{|c|c|c|c|}
\hline Thyroid Status & Smoker & Non-Smoker & Total \\
\hline Euthyroid & $68(56.1 \%)$ & $8(6.7 \%)$ & $76(62.8 \%)$ \\
\hline SCH & $10(8.3 \%)$ & $1(.8 \%)$ & $11(9.1 \%)$ \\
\hline Hypothyroidism & $32(26.5 \%)$ & $1(.8 \%)$ & $33(27.3 \%)$ \\
\hline Hyperthyroidism & $1(.8 \%)$ & 0 & $1(.8 \%)$ \\
\hline \multicolumn{4}{|c|}{ Table 5. Comparison of Thyroid Dysfunction among Smoker and }
\end{tabular}

Non-Smoker COPD Patients

\begin{tabular}{|c|c|c|c|c|}
\hline \multicolumn{2}{|c|}{ Thyroid Status } & No. & Mean FEV1 & P value \\
\hline \multicolumn{2}{|c|}{ Euthyroid } & 76 & $59.96 \pm 24.39$ & \\
\hline \multicolumn{2}{|c|}{ Thyroid dysfunction } & 45 & $54.00 \pm 23.24$ & .000 \\
\hline \multicolumn{5}{|c|}{$\begin{array}{c}\text { Table 6. Comparison of Mean FEV1 (Postmed) in Euthyroid with } \\
\text { Thyroid Dysfunction in COPD Patients }\end{array}$} \\
\hline \multicolumn{5}{|c|}{$\begin{array}{l}\text { Mean FEV1 (postmed) was higher in euthyroid COPD patients as compared to } \\
\text { thyroid dysfunction COPD patients }(\mathrm{P}<0.05) \text {. }\end{array}$} \\
\hline Sex & \multicolumn{2}{|c|}{ Total No. } & \multicolumn{2}{|c|}{ Thyroid Dysfunction } \\
\hline Male & \multicolumn{2}{|c|}{$90(74.38 \%)$} & \multicolumn{2}{|c|}{$33(36.7 \%)(\mathrm{n}=33 / 90)$} \\
\hline Female & \multicolumn{2}{|c|}{$31(25.62 \%)$} & \multicolumn{2}{|c|}{$12(38.7 \%)(\mathrm{n}=12 / 31)$} \\
\hline & \multicolumn{2}{|c|}{$121(100 \%)$} & \multicolumn{2}{|c|}{$45(37.2 \%)(n=45 / 121)$} \\
\hline
\end{tabular}

\begin{tabular}{|c|c|c|}
\hline Smoking Status & Total No. of Patients & Thyroid Dysfunction \\
\hline Smoker & $111(91.73 \%)$ & $43(38.73 \%)$ \\
\hline Non smoker & $10(8.27 \%)$ & $2(20 \%)$ \\
\hline \multicolumn{2}{|c|}{ Table 8. Comparison of Thyroid Dysfunction among Smoker and } \\
Non-Smoker COPD Patients \\
\hline
\end{tabular}

In group A out of 31 patients $70.96 \%$ were male and $29.04 \%$ were female whereas in group B out of 32 patients $75 \%$ were male and $25 \%$ were female and in group C out of 30 patients $76.66 \%$ were male and $23.34 \%$ were female and in group D out of 28 patients $75 \%$ were male and $25 \%$ were female. Further, it can be observed that mean age in group A $56.32 \pm 6.78$ years, in group B $59.69 \pm 9.61$ years, in group $C$ $62.03 \pm 8.92$ years, $65.39 \pm 7.81$ years in group D.

Mean BMI $(21.62 \pm 1.13)$ was higher in group B as compare to all group though the difference in mean BMI was not found to be statistically significant $(\mathrm{P}>0.05)$. Mean FT3 and FT4 value in group A was higher than all though the difference was not found to be statistically significant $(\mathrm{P}>0.05)$. Mean TSH(5.3991 \pm 2.9079$)$ was higher in group C as compare to all group though the difference in TSH was not found to be statistically significant $(\mathrm{P}>0.05)$.

\section{DISCUSSION}

The aim of our study was to find out the prevalence of thyroid dysfunction in patients with COPD and assess the severity of thyroid dysfunction with COPD. The study was carried out on 121 subjects who were diagnosed as a case of COPD patients. Each subject was screened to fulfil the exclusion and inclusion criteria. Various investigation and tests were performed to diagnose co morbidities mentioned as per the GOLD guidelines. The subjects were selected randomly from the IPD and OPD. No age and sex distribution were made. The mean age of COPD patients in group A was $56.2 \pm 6.8$ years, in group B was $59.7 \pm 9.6$ years, in group C was $62.1 \pm 8.9$ years and in group D was $65.4 \pm 7.8$ years. Majority of patients were in the age group of 51-60 years is (42.1\%). Among 121 patients, 90 were male and 31 were female with male predominance to male and female ratio of 2.9/1. In our study mean BMI, mean FT3, mean FT4 and TSH was comparable $(\mathrm{P}>0.05)$.Singh et al. $(2016)^{8}$ evaluated a total of 201 cases of COPD of which 130 (64.6\%) were having thyroid disorders. Hypothyroidism was diagnosed in 119 (59.2\%) cases and hyperthyroidism in 11 (5.4\%) cases. $71(35.3 \%)$ cases were found to be normal on thyroid function tests P-value of association of COPD and thyroid disorders was 0.213. Prevalence of thyroid disorder was 8.6\% (Stage A) $22.7 \%$ (Stage B), 32.5\% (Stage C), 32.7\% (Stage D). The prevalence of thyroid dysfunction was higher in higher stages of COPD as compared to that in lower stages of COPD this difference was significant statistically $(\mathrm{P}=$ 0.047).In our study the prevalence of thyroid disorder in group A is $25.8 \%$, group B is $37.5 \%$, group C is $46.7 \%$ and group D had $39.3 \%$ which was suggestive of our study. In similar study done by SC Chaudhary et al; in $2018^{9}$ Out of 171 patients, thyroid dysfunction was present in 43 patients. All of them were hypothyroid. The prevalence of thyroid dysfunction was $25 \%$. In Stage A it was $20.5 \%$, Stage B $25.7 \%$, Stage C $23.4 \%$ and in Stage D 30.4\%. Thyroid dysfunction was associated with more frequent exacerbation. In our study 44 (36.4\%) patients had TSH levels above cutoff levels (hypothyroidism and subclinical hypothyroidism). One of the patients had TSH LEVELS below cut-off level and T3/T4 levels above cut-off level hence one case of hyperthyroidism was recorded. The overall prevalence of thyroid dysfunction in our study is found to be $37.2 \%$ $(n=45 / 121)$. Prevalence of thyroid disorder is $38.7 \%$ $(n=12 / 31)$ in females as compared to $36.67 \%(n=33 / 90)$ in males. In our study group A COPD patient having thyroid dysfunction is 8 (25.8\%), group B is $12(37.5 \%)$, group C is $14(46.66 \%)$ and in group D is 11 (39.28\%).As COPD stages increases, thyroid dysfunction increases which is suggestive of our study. In our study the euthyroid COPD patients is $62.8 \%$ with subclinical hypothyroidism is $9.1 \%$, hypothyroidism is $27.3 \%$ and hyperthyroidism is $0.8 \%$. In our study the value of mean FEV1 in euthyroid COPD patients is $59.96 \pm 24.39$ and patients having thyroid dysfunction mean FEV1 is $54.00 \pm 23.24$ with significant mean FEV1 (postmed) between groups p-value $(.000<0.05)$. In our study, a total of 121 COPD patients were enrolled out of which 90 were male 
and 31 were female and depending on smoking history nonsmokers were 10 and 111 were smokers. In our study 111 smokers COPD patients having thyroid dysfunction is 43 (38.73\%) while 10 non-smokers COPD patients having thyroid dysfunction is 2 (20\%). Sarinc Ulasli et al., in 201310 did a study in which they studied 128 patients and showed that TSH values and exacerbation frequency have a positive correlation $(\mathrm{p}<0.0001 ; \mathrm{r}=0.82)$.

Prakash et al. in 2014 conducted a study and 96 cases of acute exacerbation of COPD were analysed, and he found that $62(64.58 \%)$ patients had lower levels of T3, T4, and TSH and even lower during the exacerbation stage and more significantly in above 60 years of age group. In our study the value of mean FEV1 in euthyroid COPD patients is $59.96 \pm 24.39$ and patients having thyroid dysfunction mean FEV1 is $54.00 \pm 23.24$ with significant mean FEV1 (postmed) between groups p-value $(.000<0.05)$.

A similar study conducted on Indian population by Bhattacharyya et al (2011) concluded that mean age of COPD patients was $65.32 \pm 9.58$ years which is comparable to our study. In study conducted by Yilmaz et al (2015) 21 the mean age of the patients was $62.1 \pm 8.9$ years. $74.4 \%$ of the patients were male to female ratio of the study is $2.9: 1$. The reason for this difference is that in India, COPD is more prevalent among males due to a higher prevalence of smoking among males as compared to females. In our study mean BMI in group A is $21.61 \pm 1.08$, in group B is $21.62 \pm 1.13$, in group C 21.17 \pm 1.08 and group D mean BMI of COPD patients is $21.24 \pm 1.16$ with p-value is 0.237 . In our study mean FT3 in group A COPD patient is $2.18 \pm 0.65$, in group $B$ is $2.07 \pm 0.63$, in group $C$ is $1.93 \pm 0.90$ and group $D$ is $1.77 \pm 0.47$ with insignificant FT3 difference between groups as p-value is 0.937 . In our study mean FT4 in group A COPD patient is $1.06 \pm 0$. 25, in group B is. $094 \pm 0.27$, in group $C$ is $0.91 \pm 0.35$ and group $D$ is $0.94 \pm 0.27$ with insignificant FT4 difference between groups as p-value is 0.523 . In our study mean TSH in group A COPD patient is $3.8393 \pm 2.2927$, in group B is $4.3842 \pm 2.3243$, in group $C$ is $5.3991 \pm 2.9079$ and in group $D$ is $4.9516 \pm 2.9823$ with insignificant mean TSH difference between groups as $\mathrm{p}$ value is 0.275 . In our study mean BMI, mean FT3, mean FT4 and mean TSH is comparable.

\section{Limitation of Our Study}

This is a single centre study. The number of patients enrolled in our study is small and no follow up was there, hence this study might need validation on a much larger scale for exact estimation of prevalence of thyroid dysfunction. Further, a prospective study may be needed to see the effect of thyroid dysfunction on COPD, its effect on the duration of hospital stay and mortality and morbidity and long-term study to see the change/transformation as euthyroid state to thyroid dysfunction.

\section{CONCLUSIONS}

1. As the staging of COPD increases, thyroid disorders also increase.
2. Hypothyroidism was more than subclinical hypothyroidism/ hyperthyroidism.

3. Thyroid disorder was more in female COPD patients than male patients.

4. Thyroid disorder was more in smoker-COPD patients than non-smoker-COPD patients.

5. Mean FEV1 decreased more in COPD patients with thyroid disorder than in euthyroid COPD patients.

6. Mean FEV1 decreased more in COPD patients with hypothyroidism than COPD patients with subclinical hypothyroidism/ hyperthyroidism.

As the stage of severity of COPD increases, thyroid dysfunction (hypothyroidism/subclinical hypothyroidism) was increasing and these results will guide us to monitor and treat thyroid dysfunction in patients of COPD.

\section{REFERENCES}

[1] GOLD, Global initiative for chronic Obstructive Lung Disease: Global Strategy for the diagnosis, management and prevention of chronic obstructive pulmonary disease, 2011: p. 1-50.

[2] Uzun K, Atalay H, Inal A. Thyroid hormone levels in patients with acute exacerbation of chronic obstructive pulmonary disease. Eur J Gen Med 2007;4(2):80-2.

[3] Banks WA, Cooper JA. Hypoxia and hypercarbia of chronic lung disease: minimal effects on anterior pituitary function. South Med J 1990;83(3):290-3.

[4] Gow SM, Seth J, Beckett GJ, et al. Thyroid function and endocrinological abnormalities in elderly patients with severe chronic obstructive lung disease. Thorax 1987;42(7):520-5.

[5] De Groot LJ. Dangerous dogmas in medicine: the nonthyroid illness syndrome. J Clin Endocrinal Metab 1999;84(1):151-64.

[6] Creutzberg EC, Casaburi R. Endocrinological disturbances in chronic obstructive pulmonary disease. Eur Respir J Suppl 2003;22(Suppl 46):76s80s.

[7] Prakash R, Harish M, Suryanarayana V, et al. Evaluation of thyroid functions in chronic obstructive pulmonary disease. World Journal of Medical Sciences 2014;11(1):57-8.

[8] Singh L, Jain A, Agrawal A, et al. A study of prevalence of thyroid disorders in chronic obstructive pulmonary disease patients at a tertiary care center in U.P. Int J Contemp Med Res 2016;3(5):1239-42.

[9] Chaudhary SC, Ahmad T, Usman K, et al. Prevalence of thyroid dysfunction in chronic obstructive pulmonary disease patients in a tertiary care center in North India. J Family Med Prim Care 2018;7(3):584-8.

[10] Ulasli SS, Bozbas SS, Ozen ZE, et al. Effect of thyroid function on COPD exacerbation frequency: a preliminary study. Multidiscip Respir Med 2013;8(1):64. 